\title{
Functional aerobic capacity and body size
}

\author{
W T HOULSBY \\ Department of Paediatrics, University of Sheffield
}

SUMmARY An endurance treadmill exercise test protocol of two minute stages of increasing speed and gradient has been designed and evaluated for children under 10 years of age. There was a significant relation between test protocol time and oxygen uptake measured in $\mathrm{ml} / \mathrm{kg} / \mathrm{min}$ in tests performed on 20 subjects.

One hundred and sixty exercise tests performed in a semi longitudinal study of healthy primary schoolchildren were used to assess the relation of functional aerobic capacity with age and size. In boys functional aerobic capacity measured by predicting maximal oxygen uptake from endurance time in the treadmill test increased from $33.8 \mathrm{ml} / \mathrm{kg} / \mathrm{min}$ at age 5 to $50.5 \mathrm{ml} / \mathrm{kg} / \mathrm{min}$ at age 9.5 and was most closely related to age. The variables of size were not significant in predicting functional aerobic capacity for boys. In girls functional aerobic capacity increased from 34.9 to 43.5 $\mathrm{ml} / \mathrm{kg} / \mathrm{min}$ at the same ages and was related positively to lean body mass and age but negatively to weight. For girls lean body mass contributed $53.9 \%$ to the variance of functional aerobic capacity in stepwise multiple regression, weight $7 \cdot 7 \%$, and age $3 \cdot 5 \%$. A significant difference between the sexes was found.

Endurance treadmill exercise testing may be used to assess physical fitness, the endurance time in a standardised test protocol being proportional to maximal oxygen uptake or aerobic capacity. Standards are not readily available, however, for children in the United Kingdom.

The Bruce protocol test, in which the subject exercises to exhaustion on a treadmill through a fixed protocol of three minute stages of increasing speed and gradient, has been used in both adult and paediatric practice. ${ }^{12}$ Experience with this test in children under 10 years of age has, however, revealed practical difficulties. The work increments between successive stages are too great, resulting in endurance times that are biased towards the first half of the current stage. Children aged under 10 only rarely achieve the fifth stage of the Bruce protocol, confirming the observations of Cumming et $a l,{ }^{2}$ and never the sixth or seventh stages. Thus the time from the 12th to the 21st minute is effectively unused. The three minute stages are too long for young subjects, who become bored waiting for the next increment. Finally, the increments of work between stages, calculated from the treadmill speed and gradient, are unequal, leading to the need for several linear regression equations or a complex power equation to predict functional aerobic capacity. ${ }^{3}$
A similar type of test protocol, retaining the undoubted advantages of this form of treadmill test ${ }^{2}$ has therefore been designed with young children in mind. This paper describes the test, the relation between protocol time and oxygen uptake, and a semi longitudinal survey of British primary schoolchildren that provides a provisional range for physical fitness measured in terms of functional aerobic capacity, which is expressed as predicted maximal oxygen uptake in normal children aged between 5 and 9 and its relation with body size.

\section{Subjects and methods}

Normal children from three primary schools in Sheffield were invited to join the study. They were recruited at the age of 5,6 , or 7 years, and exercise tests were performed at six monthly intervals over a two year period.

At the first visit a full clinical history was taken and a clinical examination performed to exclude any child with chronic disease and to determine pubertal state. The child's usual daily pattern of activity was established, noting particularly any special physical activity not in the normal school timetable, whether the child was taking part in the normal school physical education lessons, and any time spent outside school hours in team sports or training 
sessions. The extent of the parents' participation in sports and physical activity was also explored.

At subsequent visits enquiries were made into recent health and clinical examinations performed if indicated. Subjects who were unwell or who were recovering from minor acute illnesses had their tests postponed until they were fully recovered.

Anthropometry. Age was calculated in years and fractions expressed as decimals. In some analyses data were grouped into half year age bands; an age between 6.25 and 6.74 years would be in the 6.5 year band. When two tests were performed on the same subject while in the same age band the data from one only were included, the test being chosen randomly.

Height and sitting height were measured to the nearest completed millimetre. Subischial leg length was calculated. Standard deviation scores for height, sitting height, and leg length were calculated from nationally accepted data. ${ }^{4}$ Weight was measured to the nearest completed $50 \mathrm{~g}$. Skinfold thickness was measured at four sites on the left side of the body. Mid-triceps, mid-biceps, subscapular, and suprailiac folds were measured to the nearest completed 10th of a millimetre. Body density, percentage fat, and hence lean body mass were calculated from weight and skinfold thickness measurements using formulas developed for children. ${ }^{5}$

Spirometry. Single expired breath spirometry was performed before and five minutes after the end of exercise. Peak expiratory flow rate was recorded as the best attempt of three after instruction using a Wright Peak Flow Meter.

Exercise testing. Table 1 describes the endurance exercise test protocol of two minute stages of increasing speed and gradient. The electrocardiogram was monitored throughout the exercise test, and 10 second permanent records were made at the end of each minute of the test and at the child's

Table 1 The endurance exercise test protocol

\begin{tabular}{llll}
\hline $\begin{array}{l}\text { Two minute } \\
\text { stage }\end{array}$ & $\begin{array}{l}\text { Speed } \\
(\mathrm{km} / \mathrm{h})\end{array}$ & $\begin{array}{l}\text { Gradient } \\
(\%)\end{array}$ & $\begin{array}{l}\text { Theoretical } \\
\text { workload } \\
(\mathrm{kpond} \mathrm{m} / \mathrm{min})\end{array}$ \\
\hline 1 & $3 \cdot 0$ & 10 & $5 \cdot 0$ \\
2 & $3 \cdot 8$ & 12 & $7 \cdot 5$ \\
3 & $4 \cdot 3$ & 14 & $10 \cdot 0$ \\
4 & $4 \cdot 7$ & 16 & $12 \cdot 5$ \\
5 & $5 \cdot 0$ & 18 & $15 \cdot 0$ \\
6 & $5 \cdot 5$ & 19 & $17 \cdot 5$ \\
7 & $6 \cdot 0$ & 20 & $20 \cdot 0$ \\
8 & $6 \cdot 4$ & 21 & $22 \cdot 5$ \\
9 & $6 \cdot 8$ & 22 & $25 \cdot 0$ \\
\hline
\end{tabular}

point of exhaustion, from which the heart rates were later calculated.

The test was supervised at all times by two persons, the author and one of two assistants, both experienced paediatric nurses and trained in techniques of exercise testing and resuscitation.

As the speed and gradient increased the child was encouraged to walk and then jog or run until exhausted. The end point for exhaustion, or endurance time, was largely determined by the child's subjective experience, but certain objective criteria were also used whenever possible. A heart rate of at least 195 beats/min was aimed for. ${ }^{6}$ Cold sweating, facial pallor, particularly circumoral pallor, unsteadiness of gait, or incoordination and faintness were used as signs of impending central cardiovascular exhaustion, ${ }^{7}$ as opposed to peripheral limitation, which presents with fatigue, pain, and muscle weakness. It is emphasised, however, that despite non-achievement of these objective criteria a child's unwillingness to proceed further, hanging onto the hand rail, or becoming distressed was interpreted as an indication of having reached functional exhaustion, the psychological component of physical fitness being considered important. The predicted oxygen uptake at this point was termed the functional aerobic capacity.

Oxygen uptake. Oxygen uptake was measured in a subgroup drawn from the study population. A commercially available system (Oxycon 4, Gebr Mijnhardt BV, Odjic, Netherlands) was used. Oxygen uptake expressed as $\mathrm{ml} / \mathrm{kg} / \mathrm{min}$ was measured continuously and averaged over 30 second periods throughout the tests.

Statistical methods. Data were analysed by Student's $t$ test and conventional multiple regression techniques, implemented by the statistical package Minitab (Copyright, Pennsylvania State University, 1982).

\section{Results}

Oxygen uptake. Twenty tests on 11 boys and nine girls aged between 6.2 and 9.9 years were performed. In both sexes there was a highly significant relation between protocol time and measured oxygen uptake $(r=0.95$ for boys and 0.92 for girls). As there was no significant difference between the values for either sex $(t$ test, $\mathrm{p}>0 \cdot 1)$ the data were pooled and the following regression equation obtained:

oxygen uptake $(\mathrm{ml} / \mathrm{kg} / \mathrm{min})=14 \cdot 79+2 \cdot 50 \times$ endurance time $(\mathrm{min})$. 
This was a highly significant linear relation $(r=0.93$, residual $\mathrm{SD}=2 \cdot 44, \mathrm{p}<0.001$ ); therefore, functional aerobic capacity could be predicted directly from endurance time in the test.

There were no significant differences between the measured oxygen uptakes found in this study and the theoretical values predicted by the equation given by the International Committee for the Standardisation of Physical Fitness Tests. ${ }^{8}$

Functional aerobic capacity. Altogether 160 tests were performed on 57 children ( 27 boys and 30 girls). Seventy four tests were carried out on boys and 86 on girls. The age range of the subjects was 4.9-9.9 years. No child had an unusual exercise pattern, and none was excused school games or physical education. No parent did other than occasional recreational exercise.

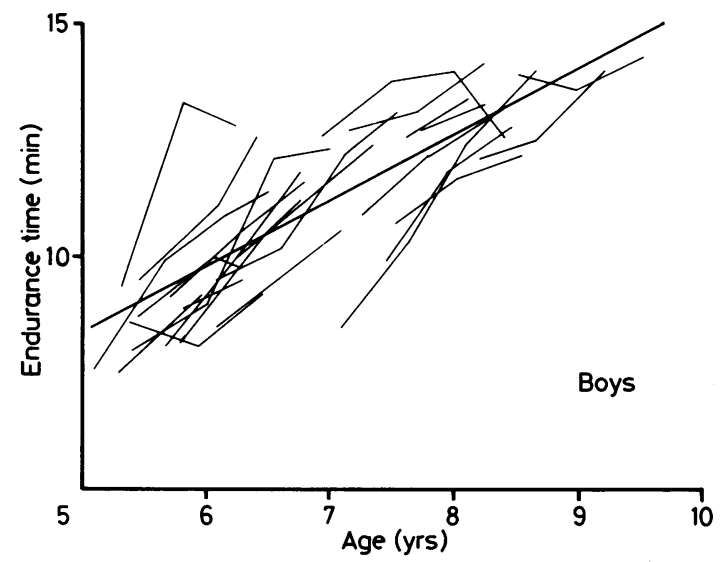

Fig. 1 Endurance time and age for boys.

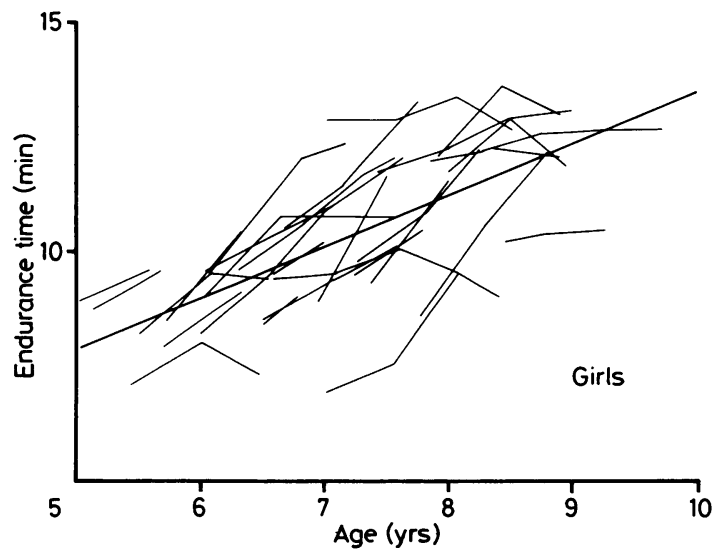

Fig. 2 Endurance time and age for girls.
All the subjects were normally grown, and none was disproportionate. All were prepubertal throughout the study and of European ethnic origin.

The maximum (SD) heart rate achieved at the end of maximal exercise was $201 \cdot 1(8.9)$ beats/min for boys and $202 \cdot 2(10 \cdot 1)$ beats/min for girls. The relation between maximum heart rate and age was not significant. Similarly, there was no correlation between maximum heart rate and endurance time.

Figures 1 and 2 show individual endurance times with the regression line for endurance time against age for boys and girls. Figure 3 shows the means and standard deviations for endurance time and hence predicted maximal oxygen uptake in each half year age band for boys and girls separately.

For boys the regression equation was: endurance time $(\min )=1 \cdot 24+1 \cdot 42 \times$ age $(y r s)$.

This correlation was significant $(r=0 \cdot 816$, residual $\mathrm{SD}=1 \cdot 12, \mathrm{p}<0 \cdot 01)$. For girls the regression equation was:

endurance time $(\min )=2 \cdot 55+1 \cdot 08 \times$ age $(y r s)$.

This relation was also significant $(r=0 \cdot 683$, residual $\mathrm{SD}=1 \cdot 57, \mathrm{p}<0 \cdot 01)$.

At age 5.0 years the mean endurance time for boys was $7 \cdot 6$ minutes, corresponding to a maximal oxygen uptake of $33.8 \mathrm{ml} / \mathrm{kg} / \mathrm{min}$. For girls the mean endurance time was 8.0 minutes, corresponding to a

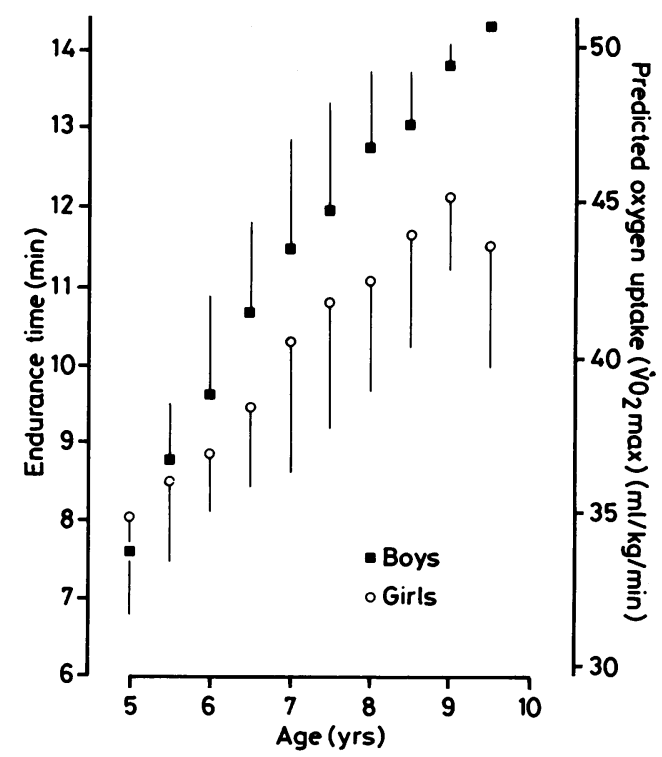

Fig. 3 Mean and standard deviation for endurance time and predicted functional aerobic capacity for boys and girls in half year age bands. 
maximal oxygen uptake of $34.9 \mathrm{ml} / \mathrm{kg} / \mathrm{min}$. At age $9 \cdot 5$ years the mean endurance time for boys was $14 \cdot 3$ minutes and for girls was 11.5 minutes, corresponding to maximal oxygen uptakes of 50.5 and 43.5 $\mathrm{ml} / \mathrm{kg} / \mathrm{min}$, respectively.

In age bands $6 \cdot 5,8 \cdot 0,8 \cdot 5$, and 9.0 years the difference between endurance times for boys and girls was significant $(t$ test, $\mathrm{p}<0 \cdot 05)$. At the other ages the difference between the sexes was not significant at the $5 \%$ level.

Using multiple regression for boys age was the only significant predictor of endurance time (Table 2). Altogether, $69.5 \%$ of the variance of endurance time was predicted by the regression, and of this

Table 2 Multiple regression analysis of relation between endurance time and age and anthropometric measurements for boys, girls, and both sexes

\begin{tabular}{|c|c|c|c|}
\hline & $\begin{array}{l}\text { Regression } \\
\text { coefficient }\end{array}$ & $\begin{array}{l}\text { Sum of squares } \\
\text { explained by } \\
\text { variable }\end{array}$ & $\begin{array}{l}p \\
\text { Value }\end{array}$ \\
\hline \multicolumn{4}{|l|}{ Boys: } \\
\hline Constant & $-2 \cdot 56$ & & \\
\hline Age (yrs) & 1.29 & $179 \cdot 17$ & $<0 \cdot 01$ \\
\hline Height $(\mathrm{cm})$ & 0.05 & $2 \cdot 15$ & NS \\
\hline Leg length $(\mathrm{cm})$ & $0 \cdot 08$ & 0.97 & NS \\
\hline Weight (kg) & -0.23 & $2 \cdot 91$ & NS \\
\hline Lean body mass $(\mathrm{kg})$ & $0 \cdot 26$ & 1.92 & NS \\
\hline Residual SD & $1 \cdot 10$ & $82 \cdot 08$ & \\
\hline \multicolumn{4}{|l|}{ Girls: } \\
\hline Constant & $3 \cdot 24$ & & \\
\hline Age (yrs) & 0.45 & 8.74 & $<0 \cdot 05$ \\
\hline Height $(\mathrm{cm})$ & $-0 \cdot 06$ & $0 \cdot 16$ & NS \\
\hline Leg length $(\mathrm{cm})$ & 0.07 & $0 \cdot 51$ & NS \\
\hline Weight $(\mathrm{kg})$ & -0.34 & $19 \cdot 14$ & $<0 \cdot 01$ \\
\hline Lean body mass $(\mathrm{kg})$ & 0.77 & $113 \cdot 43$ & $<0 \cdot 01$ \\
\hline Residual SD & $1 \cdot 04$ & $85 \cdot 70$ & \\
\hline \multicolumn{4}{|l|}{ Both sexes: } \\
\hline Constant & $0 \cdot 23$ & & \\
\hline Age (yrs) & 0.90 & $289 \cdot 39$ & $<0 \cdot 01$ \\
\hline $\operatorname{Sex}^{*}$ & $1 \cdot 17$ & $14 \cdot 74$ & $<0 \cdot 01$ \\
\hline Height $(\mathrm{cm})$ & $-0 \cdot 01$ & $11 \cdot 51$ & NS \\
\hline Leg length (cm) & $0 \cdot 01$ & 0.82 & NS \\
\hline Weight $(\mathrm{kg})$ & $-0 \cdot 30$ & 1.89 & $<0 \cdot 01$ \\
\hline Lean body mass $(\mathrm{kg})$ & 0.55 & $26 \cdot 24$ & $<0 \cdot 01$ \\
\hline Residual SD & $1 \cdot 11$ & $186 \cdot 91$ & \\
\hline
\end{tabular}

${ }^{*}$ Boy $=1$, girl $=0$.

Table 3 Stepwise regression of girls' endurance times against age and anthropometric variables (three steps only were necessary, the remaining variables not contributing significantly)

\begin{tabular}{lllllll}
\hline Step & \multicolumn{3}{l}{ Regression coefficients } & & \multicolumn{1}{r}{ Value } \\
\cline { 2 - 6 } & Constant & $\begin{array}{l}\text { Lean } \\
\text { body } \\
\text { mass } \\
(\mathrm{kg})\end{array}$ & $\begin{array}{l}\text { Weight } \\
(\mathrm{kg})\end{array}$ & $\begin{array}{l}\text { Age } \\
\text { (yrs) }\end{array}$ & $\begin{array}{l}\text { Residual } \\
\text { SD }\end{array}$ & \\
& & & & & \\
\hline 1 & 1.92 & 0.43 & & & 1.17 & 0.734 \\
2 & 1.70 & 0.85 & -0.33 & & 1.07 & 0.785 \\
3 & 0.91 & 0.71 & -0.33 & 0.46 & 1.03 & 0.807 \\
\hline
\end{tabular}

Table 4 Stepwise regression of endurance times for boys and girls against age, sex, and anthropometric variables (four steps only were necessary, the remaining variables not contributing significantly)

\begin{tabular}{|c|c|c|c|c|c|c|c|}
\hline \multirow[t]{2}{*}{ Step } & \multicolumn{6}{|c|}{ Regression coefficients } & \multirow{2}{*}{$\begin{array}{l}r \\
\text { Value }\end{array}$} \\
\hline & Constant & $\begin{array}{l}\text { Age } \\
\text { (yrs) }\end{array}$ & Sex* & $\begin{array}{l}\text { Lean } \\
\text { body } \\
\text { mass } \\
(\mathrm{kg})\end{array}$ & $\begin{array}{l}\text { Weight } \\
(\mathrm{kg})\end{array}$ & $\begin{array}{l}\text { Residual } \\
\text { SD }\end{array}$ & \\
\hline 1 & $2 \cdot 56$ & $1 \cdot 15$ & & & & $1 \cdot 32$ & 0.693 \\
\hline 2 & 1.35 & $1 \cdot 24$ & $1 \cdot 13$ & & & $1 \cdot 20$ & 0.756 \\
\hline 3 & 0.64 & 0.91 & $1 \cdot 08$ & $0 \cdot 16$ & & $1 \cdot 16$ & 0.776 \\
\hline 4 & 0.09 & 0.90 & $1 \cdot 17$ & 0.56 & $-0 \cdot 30$ & $1 \cdot 10$ & $0 \cdot 805$ \\
\hline
\end{tabular}

${ }^{*}$ Boy $=1$, girl=0.

fraction $95.8 \%$ was attributable to age. Thus age contributed $66 \cdot 6 \%$ to the total variance of functional aerobic capacity, and the other variables only contributed a further $2.9 \%$.

In girls the analysis showed a different pattern of relation (Table 2). Stepwise regression showed that lean body mass, age, and weight were significant predictors of endurance time (Table 3 ). Thus, of the $65.4 \%$ of the variance of endurance time explained by the regression equation (almost the same proportion as for boys), $82 \cdot 1 \%$ was contributed by lean body mass, $11.7 \%$ by weight, and $5.3 \%$ by age. Hence lean body mass contributed to $53.9 \%$ of the total variance of functional aerobic capacity, weight $7 \cdot 7 \%$, and age $3.5 \%$.

When sex was taken into account alongside age and the anthropometric variables as a factor predicting endurance time it was also found to be significant (Table 2), confirming the differences in functional aerobic capacity between the sexes shown when the data were analysed in age bands (Fig. 3). Stepwise regression (Table 4) showed that of the $64.9 \%$ of the total variance of endurance time that was explained by the regression equation, $74 \cdot 1 \%$ was due to age and a further $14 \cdot 1 \%$ was due to sex. Hence $9.1 \%$ of the total variance of functional aerobic capacity was attributable to sex.

\section{Discussion}

Work physiologists generally agree that measurement of maximal oxygen uptake is the standard for assessment of physical fitness, ${ }^{9}$ but they do not agree about the criteria for having attained this. Asstrand, and others since, have required their subjects to have accumulated a substantial oxygen debt measured in terms of blood lactate concentration. ${ }^{10}$ Blood sampling, even taking a capillary sample, from the normal children in this study for non-therapeutic purposes could not be 
justified ethically. In addition, a traumatic experience might have diminished cooperation. Other workers have required a plateau of oxygen uptake despite increasing workloads, ${ }^{11}$ and yet others recognise that the plateau is difficult if not impossible to achieve in children and allow the subject to decide his own functional end point. ${ }^{2}{ }^{12}$ This is the present author's choice of end point and is the reason for the term 'functional aerobic capacity' being used.

The design of the test protocol was evaluated by measuring oxygen uptake directly during tests to predict maximal oxygen uptake from endurance time. A linear relation of oxygen uptake with test protocol time has been found; functional aerobic capacity was, therefore, predicted directly from endurance time.

In terms of their physiological responses the children studied seemed to be normal and healthy. Their spirometric measurements at rest were nor$\mathrm{mal}$, and the response to exercise was within normal limits apart from in seven out of the total of 180 tests when mild exercise induced bronchospasm was detected. In only two cases was this symptomatic, and the onset of symptoms was after the end of the exercise test. The maximum heart rate achieved at the end of maximal exercise in the group as a whole was within the accepted range of normal. ${ }^{9}$ In no case was heart rate alone used as a criterion of maximal effort. A child showing other subjective or objective signs of impending exhaustion was considered to have performed to his or her limit even in the absence of achieving the heart rate of 195 beats/min that has been regarded as a minimum target. ${ }^{6}$ Similarly, a child achieving a heart rate of 210 beats $/ \mathrm{min}$, or in one case over 220 beats $/ \mathrm{min}$, without showing signs of central exhaustion was encouraged to continue until showing these signs.

The pattern of development seen was of an increase in functional aerobic capacity with increasing age and size. It was related most strongly to age in boys and to lean body mass in girls. At the younger ages there was little difference between the values for both sexes, but as age increased the differences became significant. When analysed in half year age bands the values at ages $6 \cdot 5,8 \cdot 0,8 \cdot 5$, and 9.0 were significantly different.

Analysis of the variance of endurance time by multiple stepwise regression showed that for boys endurance time, and thus functional aerobic capacity, was predicted significantly by age alone. For girls, however, lean body mass, weight, and age were all significant variables, endurance time being influenced positively by lean body mass and age but negatively by weight. This does not confirm the suggestion that analysis by multiple regression has no advantage to offer over the more straightforward method of linear regression in predicting functional aerobic capacity. ${ }^{13}$ It does, nevertheless, fit in with the clinical impression that, although the older boys tended to have longer endurance times whatever their size or shape, it was the less 'podgy' girls who had greater functional aerobic capacities.

These data are compatible with the findings of previous studies, largely of North American and Scandinavian origin, in which an increase in aerobic capacity with age was noted. ${ }^{214-17}$ They do not concur with others who have found no difference in maximal oxygen uptake with age in prepubertal children. ${ }^{10} 13$ The significant differences found between the sexes, boys having significantly greater endurance times than girls when all other variables were taken into account, concurs with the findings of previous work in which greater working capacities were noted in boys than in girls of the same size. ${ }^{151618}$

There are obvious differences in the physiological responses of boys and girls. In all studies, including this one, girls have tended to achieve higher maximum heart rates. There is also evidence that in girls, particularly as they become heavier and older, there is greater participation of energy production from anaerobic metabolism than in boys. ${ }^{19}$ This may make girls less tolerant of acute exercise. It has been shown that at a given oxygen uptake girls have a higher heart rate, higher cardiac output, and lower arteriovenous oxygen difference than boys, but the differences could not be explained. ${ }^{20}$

Cultural differences between the sexes in childhood are easy to identify but hard to quantify; many girls are encouraged into more sedate pastimes. As all but the most intensive training regimens have, however, been shown to have little influence on aerobic capacity in either sex before puberty, ${ }^{21}{ }^{22}$ young girls, like young boys, probably maintain a level of spontaneous activity that leads to a fairly high degree of fitness.

It is not possible to explain fully the differences seen between boys and girls in the pattern of relations of functional aerobic capacity with age and anthropometric factors on the basis of the data collected. It is of great importance, however, to note that in both sexes there was an increase in functional aerobic capacity measured in terms of oxygen uptake per unit mass with increasing age and size, implying that there is a process of maturation of physical abilities taking place, and that functional aerobic capacity was predicted best in boys by age and in girls by lean body mass.

I thank the Trustees of the Hawley Trust and Trent Regional Health Authority for financial help and Professor R D G Milner for helpful discussions. 


\section{References}

${ }^{1}$ Bruce RA, Kusumi F, Hosmer D. Maximum oxygen uptake and nomographic assessment of functional aerobic impairment in cardiovascular disease. Am Heart J 1973;85:546-62.

2 Cumming GR, Everatt D, Hastman L. Bruce treadmill test in children: normal values in a clinic population. Am J Cardiol 1978;41:69-75.

${ }^{3}$ Foster C, Jackson AS, Pollock ML, et al. Generalised equations for predicting functional capacity from treadmill performance. Am Heart J 1984;107:1229-34.

4 Tanner JM. Physical growth and development. In: Forfar JO, Arneil GA, eds. Textbook of paediatrics. 3rd ed. Edinburgh: Churchill Livingstone, 1984:278-330.

5 Brook CDG. Determination of body composition of children from skinfold measurements. Arch Dis Child 1971:46:182-4.

${ }^{6}$ Godfrey S. The growth and development of the cardiopulmonary responses to exercise. In: Davies JA, Dobbing J, eds. Scientific foundations of paediatrics. 2nd ed. London: William Heinemann Medical Books Ltd, 1981:450-60.

7 Shephard RJ, Allen C, Benade AJS, et al. The maximum oxygen uptake-an international reference standard of cardiorespiratory fitness. Bull WHO 1968;38:757-64.

${ }^{8}$ International Committee for the Standardisation of Physical Fitness Tests. Physiological measurements and indices. In: Larson LA, ed. Fitness, health and work capacity: international standards for assessment. New York: MacMillan, 1974:469-92.

9 Åstrand P-O, Rodahl K. Textbook of work physiology. 2nd ed. New York: McGraw-Hill Book Co, 1977.

10 Åstrand P-O. Experimental studies of physical working capacity in relation to sex and age. Copenhagen: Egnar Munksgaard, 1952.

1 Taylor HL, Buskirk E, Henschell A. Maximum oxygen uptake as an objective measure of cardiorespiratory performance. J Appl Physiol 1955;8:73-80.

12 Cooper DM, Weiler-Ravell D, Whipp B, Wasserman K. Aerobic parameters of exercise as a function of body size during growth in children. J Appl Physiol 1984;56:628-34.
13 Shephard RJ, Lavallee H, La Barre R, et al. The basis of data standardisation in pre-pubescent children. In: Ostyn $\mathbf{M}$, Beunen G, Simons J, eds. Kinanthropometry II. Baltimore: University Park Press, 1980:360-70.

14 Robinson S. Experimental studies of physical fitness in relation to age. Arbeitsphysiologie 1938;10:251-323.

15 Adams FH, Linde LM, Miyake $H$. The physical working capacity of normal schoolchildren. I California. Pediatrics $1961 ; 28: 55-64$.

16 Adams FH, Bengtsson E, Berven H, Wegelius C. The physical working capacity of normal schoolchildren. II Swedish city and country. Pediatrics 1961;28:243-57.

17 Lange-Andersen K, Seliger V, Rutenfranz J, Skobak-Kaczynski J. Physical performance capacity of children in Norway. Eur J Appl Physiol 1976;35:49-58.

${ }^{18}$ Boulton J. Physical fitness in childhood and its relationships to age, maturity, body size and nutritional factors. Acta Paediatr Scand [Suppl] 1981;284:80-5.

${ }^{19}$ Macek M, Vavra J. Cardiopulmonary and metabolic changes during exercise in children 6 to 14 years old. J Appl Physiol 1971;30:200-4.

20 Bar-Or O, Shephard RJ, Allen CL. Cardiac output of 10- to 13year-old boys and girls during submaximal exercise. J Appl Physiol 1971;30:219-23.

${ }^{21}$ Cumming GR, Goulding D, Baggley G. Failure of school physical education to improve cardiorespiratory fitness. Can Med Assoc J 1969;101:69-73.

22 Lussier L, Buskirk ER. Effects of an endurance training regimen on assessment of work capacity in pre-pubertal children. Ann NY Acad Sci 1977;301:734-47.

Correspondence to Dr W T Houlsby, University Department of Paediatrics and Child Health, Clarendon Wing, General Infirmary at Leeds, Belmont Grove, Leeds LS2 9NS, England.

Received 10 January 1986 